\title{
Validation of a German Version of Kelley's (1992) Followership Questionnaire
}

\author{
Mirko Ribbat ${ }^{\oplus}$, Stefan Krumm², and Joachim Hüffmeier ${ }^{3}$ \\ 1Federal Institute for Occupational Safety and Health, Dortmund, Germany \\ ${ }^{2}$ Institute of Psychology, Free University of Berlin, Germany \\ ${ }^{3}$ Institute of Psychology, TU Dortmund University, Germany
}

\begin{abstract}
While most leadership research takes the perspective of leaders influencing their followers, more recent research focused on the question how followers may influence their leaders. Kelley's (1992) followership questionnaire was the first to assess followership behavior. To provide a basis for further research on followership in German-speaking countries, we conducted two studies to establish the psychometric properties of a German version of Kelley's questionnaire. In Study 1, we explored the factorial structure of our translation in a heterogeneous employee sample $(N=451)$. In Study 2, we tested for convergent, discriminant, and criterion-related validity in another heterogeneous employee sample $(N=413)$. The results indicate satisfactory psychometric properties for two followership dimensions (i.e., active engagement and independent, critical thinking). Correlations of these two followership dimensions with other constructs were mostly in line with our expectations. We discuss the usefulness of the German followership questionnaire for research and practice.
\end{abstract}

Keywords: followership, questionnaire validation, leadership, active engagement, critical thinking

Traditionally, leadership research has taken the perspective of leaders influencing their followers (i.e., a leader-centric view; Dinh et al., 2014; Lord et al., 2017). In contrast, the contribution of followers to the leadership process has long been neglected. In their review on followership, Uhl-Bien et al. (2014, p. 89) stated that even if "most research on leadership recognizes the follower in some way, the focus on followership as a research area in its own right has not occurred until very recently [...]." Followership can be defined as "behaviors of individuals acting in relation to a leader(s)" (Carsten et al., 2010, p. 545), including the way followers take responsibility relative to their leader, the way they communicate, or the way they try to solve problems with their leader. Uhl-Bien et al. (2014) argued that a deeper understanding of followership is essential for a better understanding of leadership because without followers there would be neither leaders nor leadership.

While Kelley (1988) already stressed the organizational value of the follower in the 1980s, empirical tests of extant theoretical approaches to followership remain scant (Oc \& Bashur, 2013; for such approaches, see, for instance, Chaleff, 1995; Hurwitz \& Hurwitz, 2015; Kellerman, 2008; Kelley, 1992). A problem that prevents progress is that only very few validated instruments to study followership are available (Baker, 2007). To the best of our knowledge,
Kelley (1992) was the first to develop a followership questionnaire. The questionnaire is based on his theoretical account, understanding followership behaviors as the followers' active engagement (AE) in the leadership process and their independent, critical thinking (ICT) toward their leader. According to Kelley (1992), the best followers actively participate in the leadership process and take initiative (AE), rather than being passive and lazy. At the same time, they think for themselves and give constructive criticism to their leader (ICT), rather than simply taking directions and requiring constant supervision. Thus, ideal followers have an adequate balance of actively accepting the follower role and questioning leaders' decisions. In this way, they contribute to leadership and, ultimately, to organizational success.

With the current research, we intend to provide a basis for further followership research in German-speaking countries by adapting and validating a German version of Kelley's (1992) followership questionnaire. We therefore translated the original English version into German and conducted two studies to validate our translation. In Study 1, we explored the factorial structure of our questionnaire. In Study 2, we tested the convergent, discriminant, and criterion-related validity of the measurement instrument. 
Our study extends current research because there is no validated questionnaire on followership behavior in German-speaking countries yet. With our study, we provide a questionnaire for researchers and practitioners to assess the followership behavior of German-speaking employees. Furthermore, we study the generalizability of prior findings in another cultural context by testing construct relationships that were also investigated in other validation studies of Kelley's instrument (Blanchard et al., 2009; Gatti et al., 2014) in a sample of German employees.

\section{The Present Research}

\section{Evidence on the Questionnaire's Structure}

Blanchard et al. (2009) conducted a validation study of Kelley's (1992) questionnaire for the original English items with a sample of faculty members at a large university. Gatti et al. (2014) conducted a validation study for their Italian translation with a sample of employees from different organizational settings. The two factors conceptualized by Kelley (1992) emerged in both studies (i.e., AE and ICT), while the items partly loaded on different dimensions than Kelley had predicted. Notably, Blanchard et al. (2009) found an additional third factor. However, they argued that the first four items of Kelley's questionnaire do not tap into follower behavior but into attitudes and affect (e.g., the first item: "Does your work help you fulfill some societal goal or personal dream that is important to you?"). They suggested eliminating these four items as the goal of Kelley's instrument is to tap into behavior. Hence, we followed the suggestion of Blanchard et al. (2009) - an approach also taken by Gatti et al. (2014). In both validation studies, the final adjusted instrument contained 14 items. Blanchard et al. (2009) reported reliabilities of $\alpha=.86$ for $\mathrm{AE}$ and $\alpha=.74$ for ICT with a factor correlation of $r=.38, p<.001$. In the Italian version, the reliabilities were $\alpha=.94$ for $\mathrm{AE}$ and $\alpha=.79$ for ICT with a factor correlation of $r=.55, p<$ .001 (Gatti et al., 2014). While Blanchard et al. (2009) did not conduct a confirmatory factor analysis (CFA) and therefore did not report model fit indices, Gatti et al. (2014) reported a model fit of $\chi^{2}(73)=296.66, p<.001$, $\chi^{2} / d f=3.90$, Comparative Fit Index $(\mathrm{CFI})=.96$, RMSEA $=.10$, and SRMR $=.07$, for a two-factorial solution. Because we chose a comparable approach to the two prior studies, we predict the following:

Hypothesis 1: Our German translation of Kelley's questionnaire will show a two-factor solution.

\section{Correlations With Other Measures}

To test whether we would obtain evidence for convergent validity, we included the following constructs: personal initiative at work (Frese et al., 1997), self-responsibility (Bierhoff et al., 2005), and subordinate influence tactics (SITs; Blickle \& Gönner, 1999).

First, personal initiative at work (Frese et al., 1997) should be associated with AE. Personal initiative is defined as a "behavior syndrome resulting in an individual's taking an active and self-starting approach to work" (Frese et al., 1997, p. 140). Personal initiative and active followership behavior both concern an individual's inclination to take action. However, personal initiative describes general proactive behavior and is not specifically directed to the leader. Thus, it differs from followership, but due to its conceptual relatedness, we expect it to be positively correlated with $\mathrm{AE}$.

Second, we included self-responsibility (Bierhoff et al., 2005) as an indicator of convergent validity for ICT. Bierhoff et al. (2005) defined self-responsibility in organizations as implying calculated risk-taking to increase organizational success by acting self-reliantly. Thus, self-responsibility and ICT focus on the self as an independent and self-contained individual. However, self-responsible action in organizations is not necessarily directed to the leader. Still, due to its conceptual relatedness, we expect a positive relation to ICT.

Third, we gauged SITs (Blickle \& Gönner, 1999). SITs refer to employees' ways to assert important issues visà-vis their leader (e.g., by using rational influence or exerting pressure). They are conceptually similar to at least one general aspect of followership behavior: SITs imply an intentional and critical approach to carry out the follower role. In sum, we expect a moderate positive correlation for all concerned relationships $(r=.50$; Cohen, 1988). Our hypotheses on convergent validity are the following:

Hypothesis 2: AE will be positively and at least moderately (i.e., $r \geq .50$; Cohen, 1988) related to (a) personal initiative at work and (b) SITs.

Hypothesis 3: ICT will be positively and at least moderately (i.e., $r \geq .50$ ) related to (a) selfresponsibility in organizations and (b) SITs.

In accordance with Gatti et al. (2014), we assess leader-member exchange (LMX) as an indicator for discriminant validity. LMX describes the development of mature relationships between leaders and followers to generate more effective leadership (Graen \& Uhl-Bien, 1995). Since LMX assesses the quality of relationships and not follower behaviors, both constructs should not overlap. Thus, we predict a weak correlation between LMX and followership, which would speak to the discriminant 
validity of Kelley's questionnaire. Thus, the correlations with LMX should not be greater than $r=.20$ (Cohen, 1988).

Hypothesis 4: AE will only be weakly $(r \leq .20$; Cohen, 1988) related to LMX.

Hypothesis 5: ICT will only be weakly $(r \leq .20)$ related to LMX.

\section{Relationship to Criteria}

We posit that followership behaviors will be related to important work-related criteria, such as work-related attitudes (job satisfaction and organizational commitment), extra-role performance (organizational citizenship behaviors [OCBs]), and emotional states (exhaustion). Job satisfaction is defined as "a pleasurable or positive emotional state resulting from the appraisal of one's job or job experiences" (Locke, 1976, p. 1304). Organizational commitment "(a) characterizes the employee's relationship with the organization, and (b) has implications for the decision to continue or discontinue membership in the organization" (Meyer \& Allen, 1991, p. 67). We draw on cognitive dissonance theory (Festinger, 1957) and predict that actively engaged followers justify the effort they spend for their work and are, thus, likely to have more positive job-related attitudes. A related argument is also made by Blanchard et al. (2009, p. 115): "Because attitudes are usually easier to change than behaviors, employees will change their attitudes to justify their behavior." As employees spend considerable effort when actively engaging in their jobs, we expect a positive relation of $\mathrm{AE}$ with job satisfaction and organizational commitment:

Hypothesis 6: AE will be positively related to (a) job satisfaction and (b) organizational commitment.

However, in accordance with Blanchard et al. (2009), we predict a negative relation of ICT with both job satisfaction and organizational commitment. Although similar effort has to be expended for ICT as for AE, we expect that ICT exerts a negative influence on attitudinal variables that also prevails over possible positive effects of effort justification. This is because ICT increases followers' awareness of the problems and negative aspects of their job. Thus, we hypothesize the following:

Hypothesis 7: ICT will be negatively related to (a) job satisfaction and (b) organizational commitment.

Organ (1988) defined OCBs as voluntary behaviors at work, which are beneficial for organizational functioning. OCBs express a certain degree of involvement in the organization, and a similar involvement also underlies both followership dimensions. According to Kelley (1992), effective followers, for instance, tend to carry out assignments that go beyond their job. They also personally identify critical activities instead of waiting for the leader's instructions. The findings of Gatti et al. (2014) also suggest a positive relation of followership with OCBs. Thus, we hypothesize the following:

Hypothesis 8: AE and ICT will be positively related to OCBs.

Emotional exhaustion refers to "feelings of being overextended and exhausted by the emotional demands of one's work" (Demerouti et al., 2001, p. 499). According to conservation of resources theory (Hobfoll et al., 1992), employees use strategies that minimize any further resource loss to cope with emotional exhaustion (Wright \& Cropanzano, 1998). Both AE and ICT require a high level of energy (e.g., when going beyond standard tasks or managing conflicts with the leader) and thereby consume personal resources. Thus, in accordance with Gatti et al. (2014), we expect negative relations of both followership dimensions with emotional exhaustion:

Hypothesis 9: AE and ICT will be negatively related to emotional exhaustion.

Finally, we also included the Big Five personality traits (McCrae \& Costa, 2003) in our study, which describe relatively stable patterns of behavior, thoughts, and emotions. They are labeled as "extraversion" (relating to attributes like sociable, gregarious, assertive, and ambitious), "neuroticism" (unstable, insecure, nervous, and highly sensitive), "openness" (perceptive, imaginative, cultured, and curious), "agreeableness" (meaning courteous, helpful, trusting, and cooperative), and "conscientiousness" (dependable, hardworking, efficient, and organized; Barrick et al., 2005). Gatti et al. (2014) reported positive correlations of both followership dimensions with extraversion. In the current study, we will test whether AE and ICT will account for variance increments in the outcome variables (i.e., job satisfaction, organizational commitment, OCBs, and emotional exhaustion) over and above the broad personality traits to check whether the two followership dimensions show incremental validity.

\section{Study 1}

The aim of Study 1 was to test whether our German version of Kelley's (1992) questionnaire fits a two-factor solution 
equivalent to the previous validation studies (Blanchard et al., 2009; Gatti et al., 2014; Hypothesis 1).

\section{Method}

\section{Participants}

We conducted an anonymous online survey via the German "SoSci Panel" (Leiner, 2016), an online respondent pool based on voluntary registration. We included only employees with a direct superior to ensure credible responses concerning followership behaviors in organizations. In addition, we tried to detect careless responses by following the procedures recommended by Meade and Craig (2012; for details, see Electronic Supplementary Material 1 [ESM 1]).

The final sample consisted of 451 employees (60.2\% women, $39.2 \%$ men, and $0.6 \%$ respondents without a gender indication; Ribbat, Krumm, \& Hüffmeier, 2020). The mean age of the participants was 42 years $(S D=$ 11.06, $M d n=42$ ). Their highest education level was as follows: $21.6 \%$ of the respondents completed an apprenticeship, $26.0 \%$ a degree from a university of applied sciences, $37.4 \%$ a university degree, $7.6 \%$ a doctoral degree, $1.1 \%$ no professional degree, and $6.3 \%$ a degree not specified in the survey. Occupations of participants covered all domains (see Holland, 1996), that is, $33.5 \%$ had social professions, $20.5 \%$ conventional professions, $19.8 \%$ enterprising professions, $12.2 \%$ investigative professions, $8.9 \%$ realistic professions, and $3.1 \%$ artistic professions. Participants' average tenure in their organizations was 11 years $(S D=10.38, M d n=7)$, and the average tenure with their leader was 5 years $(S D=4.98, M d n=3)$.

\section{Instruments}

Followership behaviors were measured with our translated German version of Kelley's (1992) questionnaire. We conducted three steps for the translation process as recommended by Bracken and Barona (1991). Details on the translation process and our translation can be found in ESM 2. Each item was answered on a 7-point rating scale. Possible responses ranged from 1 ([almost] never) to 7 ([almost] always).

\section{Data Analysis}

For the purpose of this study, we randomly split the sample into two subsamples. We used the first subsample $(n=226)$ to explore the factorial structure and compared the results to Kelley's theoretical categorization and the findings of the other two pertinent validation studies (Blanchard et al., 2009; Gatti et al., 2014). Following Fabrigar et al. (1999), we considered the sample size as appropriate for the exploratory factor analysis (EFA), since we had a moderate level of communalities of the measured variables (with an average of .47) and expected at least three measured variables to represent each common factor.

Subsequently, we tested the adjusted final version of our questionnaire with a CFA independently in the second subsample $(n=225)$. For both factor analyses, we used Mplus 7.4 (Muthén \& Muthén, 2015) and the weighted least squares means and variance adjusted estimator (WLSMV). The goodness of fit was evaluated using the resulting chi-square values, the RMSEA, the $\mathrm{CFI}$, and the weighted root mean square residual (WRMR). Following common recommendations (Cook et al., 2009; West et al., 2012), cutoff values for a good fit were defined as $p_{\chi}{ }^{2}<.05, \chi^{2} / d f<5$, CFI $>.95$, RMSEA $<.06$, and WRMR $<1$.0. Furthermore, possible misspecifications were also detected based on modification indices and standardized expected parameters of change, as described by Saris et al. (2009). A post hoc power analysis with semPower (Moshagen \& Erdfelder, 2016) for the most complex CFA with a sample size of $n=225$ to detect an RMSEA $=.05$ revealed a power $(1-\beta)$ of .89 . We use a reliability indicator based on factor models. For each followership dimension, we report the omega subscale $\left(\omega_{\mathrm{s}}\right)$ as described by Rodriguez et al. (2016). We used Watkins' (2013) standalone program to compute $\omega_{\mathrm{s}}$.

\section{Results}

A detailed analysis of item and scale parameters can be found in ESM 3. A parallel analysis (Horn, 1965) with random normal data generation of 1,000 datasets yielded two factors. The first three raw data eigenvalues were $6.07,1.84$, and 1.00. The first three random data eigenvalues were $1.59,1.46$, and 1.36 . This was in line with the optical test of the scree plot. Table 1 shows the factor loadings of the EFA with WLMSV estimator and promax rotation. The factors correlated with $r=.50$.

Four items loaded on the factor that Blanchard et al. (2009) and Gatti et al. (2014) termed "ICT" (Factor 2). The other factor contained a mix of items that we expected - based on Kelley's (1992) theoretical considerations - to load on either AE or ICT. Blanchard et al. (2009) argued that these items describe both independent and proactive behaviors but consider the emerging factor to "most closely reflect what Kelley has proposed to be active, engaged followers" (Blanchard et al., 2009, p. 119). We agree with this assessment and accordingly term factor 1 "AE" and factor 2 "ICT." We excluded two items with comparatively weak 
Table 1. Results of factor analysis, subsample 1

\begin{tabular}{|c|c|c|c|}
\hline \multirow[b]{2}{*}{ Item } & & \multicolumn{2}{|c|}{$\begin{array}{l}\text { Factor } \\
\text { loading }\end{array}$} \\
\hline & & 1 & 2 \\
\hline \multicolumn{4}{|c|}{ Factor 1: AE } \\
\hline 10. & Contribute high level (AE) & .88 & -.16 \\
\hline 9. & Take initiative (AE) & .82 & -.12 \\
\hline 15. & Understanding the needs and objectives (AE) & .74 & -.18 \\
\hline 11. & Think up new ideas (ICT) & .71 & .17 \\
\hline 6. & Actively develop (AE) & .67 & .18 \\
\hline 8. & Highest quality work (AE) & .59 & .19 \\
\hline 7. & Build success (AE) & .55 & -.07 \\
\hline 12. & Solve tough problems (ICT) & .54 & .26 \\
\hline 16. & Recognize one's strengths and weaknesses (ICT) & .54 & .17 \\
\hline 5. & Personally identify (ICT) & .51 & .33 \\
\hline 13. & Help coworkers (AE) & .47 & .09 \\
\hline 14. & See opportunities and risks (ICT) & .45 & .17 \\
\hline \multicolumn{4}{|c|}{ Factor 2: ICT } \\
\hline 18. & Contrary (ICT) & -.18 & .74 \\
\hline 19. & Ethical standards (ICT) & -.08 & .72 \\
\hline 20. & Assert issues (ICT) & .08 & .63 \\
\hline 17. & Question decisions (ICT) & .09 & .63 \\
\hline
\end{tabular}

loadings from subsequent analyses to obtain a model that is as robust as possible. This reduced the overall instrument from 16 to 14 items.

We tested this 14-item questionnaire with a twofactorial CFA in subsample 2. The detailed results are presented in ESM 4. All factor loadings were acceptable, and the model fit was $\chi^{2}(76)=240.63, p<.001, \chi^{2} / d f=$ 3.17 , RMSEA $=.10(.08-.11)$, CFI $=.94$, and WRMR $=.96$. While not all cutoff values for a good fit were reached, this fit can still be described as reasonable (Hopwood \& Donnellan, 2010). Additionally, the fit is comparable to the findings of Gatti et al. (2014). However, the misspecification test (Saris et al., 2009) revealed some difficulties with certain items that might point to local misspecification. Detailed information is presented in ESM 5. In order to avoid overspecification by data-driven adjustments, we checked potential misspecification again in Study 2 and examined whether the same misspecifications occurred. Finally, a chi-squared difference test suggested that the two-factor solution fitted the data better than a potential one-factor solution, $\chi^{2}$ diff $(1)=$ 273.61, $p<.001$. The factors correlated with $.68(p<$ $.001)$ and showed good internal consistency. For the AE subscale factor, $\omega_{\mathrm{s}}$ was .99 ( $\left.95 \% \mathrm{CI} \pm .17\right)$, and for the ICT subscale factor, $\omega_{\mathrm{s}}$ was $.92(95 \% \mathrm{CI} \pm .58)$.

\section{Study 2}

\section{Method}

The aim of Study 2 was to test the construct- and criterionrelated validity of the translated instrument. In order to test the convergent and discriminant validity, we used two criteria. First, we inspected the magnitude of the relationships with other instruments. Since there was no other validated instrument available in German to measure followership behavior, we used measures that address followership behavior as directly as possible. We expected at least moderate correlations (i.e., $r=.50$; Cohen, 1988) of Kelley's followership behaviors with such measures. We interpret small correlations $(r \leq .20$; Cohen, 1988) with theoretically unrelated constructs as evidence for divergent validity. Second, we expected correlations with theoretically related constructs to be considerably higher than with theoretically unrelated constructs (Campbell \& Fiske, 1959).

\section{Participants}

Study 2 was again conducted via an anonymous online survey with the "SoSci Panel" (Leiner, 2016). We only included employees who had a direct superior and did not respond in a careless manner (Meade \& Craig, 2012; for details, see ESM 1).

The final sample contained 413 employees $(59.8 \%$ women, $38.7 \%$ men, and $1.5 \%$ respondents without a gender indication; Ribbat, Krumm, \& Hüffmeier, 2020). Participants' mean age was 42 years $(S D=11.49, M d n=$ 40). Their highest education level was as follows: $20.1 \%$ of the respondents completed an apprenticeship, $22.8 \%$ a degree from a university of applied sciences, $44.3 \%$ a university degree, $6.8 \%$ a doctoral degree, $2.1 \%$ no professional degree, and $4.8 \%$ a degree not specified in the survey. Occupations of participants covered all domains, that is, $33.4 \%$ had social professions, $21.1 \%$ conventional professions, $20.8 \%$ enterprising professions, $15.3 \%$ investigative professions, $6.8 \%$ realistic professions, and 2.7\% artistic professions (see Holland, 1996). The average employment in the organization was 10 years $(S D=10.13$, $M d n=6.5)$, and the average tenure with their supervisor was 5 years $(S D=5.16, M d n=3)$.

\section{Instruments}

Followership behaviors were measured with the translated German version of Kelley's (1992) questionnaire comprising 14 items, as reported in Study 1. Possible responses ranged from 1 ([almost] never) to 7 ([almost] always). We used the questionnaire by Frese et al. (1997) to measure personal initiative at work with response options ranging from not correct at all (1) to applies completely (7). Self-responsibility was measured by the scale by Bierhoff 
et al. (2005) with response options ranging from very incorrect (1) to very correct (7). The four SITs "flattering," "rational influence," "exerting pressure," and "engaging superior authority" were measured with the questionnaire by Blickle and Gönner (1999). Response options ranged from (almost) never (1) to (almost) always (7). For LMX, we used the scale by Graen and Uhl-Bien (1995) in the German version (Schyns, 2002). The response options ranged from 1 to 7 (e.g., extremely ineffective [1] to extremely effective [7]). We applied a part of the "Copenhagen Psychosocial Questionnaire" (Nübling et al., 2005) to measure job satisfaction with response options ranging from very dissatisfied (1) to very satisfied (7). Organizational commitment was assessed with the scale by Mowday et al. (1979) in the German version (Maier \& Woschée, 2002). Response options ranged from strongly disagree (1) to fully agree (7). We measured two OCBs (i.e., "helpfulness" and "initiative") with the scale by Staufenbiel and Hartz (2000). The range of possible responses was from not correct at all (1) to applies completely (7). The measure for emotional exhaustion was taken from the "Maslach Burnout Inventory" (Maslach \& Jackson, 1986) in the German version by Enzmann and Kleiber (1989). Participants were asked to indicate how often the following statements applied to them: Several times a year or rarer, once in a month, several times in a month, once a week, several times in a week, or daily. For the personality traits, we used the BFI-K instrument by Rammstedt and John (2005). Responses ranged from very wrong (1) to very true (7). Exemplary items for each instrument are provided in ESM 6.

\section{Data Analysis}

To assess the validity of the German version of Kelley's followership questionnaire, we inspected bivariate correlations with different constructs as delineated in the Hypotheses 2-9. Furthermore, we used hierarchical regression analysis to test whether AE and ICT accounted for variance increments of the criterion variables (i.e., job satisfaction, organizational commitment, OCBs, and emotional exhaustion) over and above the Big Five personality traits. A post hoc power analysis with GPower 3.1 (Faul et al., 2007) for a linear multiple regression model with a sample size of $N=413$ and seven independent variables to detect a medium $H 1 \rho^{2}=.13$ (Cohen, 1988) revealed a power $(1-\beta)$ of 1.00 .

We first computed another CFA for the followership questionnaire based on the model we specified in Study 1. The model again had a reasonable fit (Hopwood \& Donnellan, 2010): $\chi^{2}(76)=349.42, p<.001, \chi^{2} / d f=$ 4.60, RMSEA $=.09(.08-.10)$, CFI $=.93$, and WRMR $=1.22$. The misspecification detection (Saris et al., 2009) pointed to some problematic items. However, only one misspecification was identical to those reported in Study 1 .
That is, allowing residual correlations between the items "personally identify" ("Instead of waiting for or merely accepting what the leader tells you, do you personally identify which organizational activities are most critical for achieving the organization's priority goals?") and "actively develop" ("Do you actively develop a distinctive competence in those critical activities so that you become more valuable to the leader and the organization?") significantly improved model fit across both studies. Although Landis et al. (2009) advised against improving model fit through specifying residual correlations (see, however, Cole et al., 2007), we felt that the common and specific aspect of proactively making oneself valuable to the organization in both items theoretically justified this residual correlation. Note that "actively develop" was presented right after "personally identify" and phrased to directly refer to the item content of "personally identify," which is consistent with the original version of the questionnaire. Thus, we allowed that error term correlation in the model, $r=.44$, $p<.001$, which improved the model fit: $\chi^{2}(75)=302.06, p<$ $.001, \chi^{2} / d f=4.03$, RMSEA $=.09(.08-.10)$, CFI $=.94$, and $\mathrm{WRMR}=1.13$. Further details are presented in ESM 5.

We also conducted a CFA for all other measured constructs we used in Study 2. In order to avoid cross loadings of the scales, we had to delete some items from different scales for further calculations. The scales for personal initiative, self-responsibility, the SIT "flattering," LMX, job satisfaction, organizational commitment, emotional exhaustion, extraversion, neuroticism, and openness were affected by these adjustments. We used the method of ant colony optimization (ACO; Olaru et al., 2019) to identify sets of items that fit the model and thus improved construct validity. ACO allows for testing model fit and reliability criteria simultaneously for different item sets by using an iterative process inspired by the foraging of ants (Olaru et al., 2019). Further details are provided in ESM 7.

For internal consistency, we report coefficient omega $(\omega$; McDonald, 1978) and $\omega_{\mathrm{s}}$ for each dimension of multidimensional constructs (i.e., followership behaviors and OCBs). We used Mplus 7.4 (Muthén \& Muthén, 2015) to compute $\omega$ and Watkins' (2013) standalone program to compute $\omega_{s}$.

\section{Results}

Table 2 summarizes descriptive statistics, coefficients $\omega$ or $\omega_{\mathrm{s}}$ for internal consistency, and the intercorrelations of all latent models. The consistency estimates of the SIT "flattering" scale $(\omega=.69)$ and the conscientiousness scale $(\omega=.66)$ were slightly below the most commonly used minimum value of .70 . All other scales showed at least good levels of internal consistency $\left(.70 \leq \omega / \omega_{s} \leq .97\right)$. For the AE subscale factor, $\omega_{\mathrm{s}}$ was $.97(95 \% \mathrm{CI} \pm .26)$, and for 
Table 2. Descriptive statistics and correlations for study variables

\begin{tabular}{|c|c|c|c|c|c|c|c|c|c|c|c|c|c|c|c|c|c|c|c|c|c|}
\hline Variable & M & $S D$ & 1 & 2 & 3 & 4 & 5 & 6 & 7 & 8 & 9 & 10 & 11 & 12 & 13 & 14 & 15 & 16 & 17 & 18 & 19 \\
\hline 1. $\mathrm{AE}$ & 5.45 & 0.78 & .97" & $.64^{\star \star \star}$ & .10 & $.49^{\star \star \star}$ & $.18^{\star \star}$ & -.04 & $.78^{* \star \star}$ & $.72^{\star \star \star}$ & 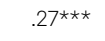 & $.36^{\star \star \star}$ & $.25^{\star \star \star}$ & $.45^{\star \star \star}$ & $.80 * \star \star$ & $-.12^{\star}$ & $.34^{\star \star *}$ & $-.28^{\star \star \star}$ & $.33^{* \star *}$ & -.04 & $.68^{* \star \star}$ \\
\hline 2. ICT & 4.85 & 0.96 & $.65^{\star \star \star}$ & $.84^{\prime \prime}$ & -.08 & $.46^{\star \star \star}$ & $.62 * \star \star$ & $.34^{\star \star \star}$ & $.56^{\star \star \star}$ & $.55^{\star \star \star}$ & -.08 & -.01 & $-.12 *$ & $.25^{\star \star \star}$ & $.58^{\star \star \star}$ & .03 & $.26^{\star \star \star}$ & $-.24^{\star \star \star}$ & $.28 * \star \star$ & $-.22^{\star \star \star}$ & $.44^{\star \star \star *}$ \\
\hline 3. SITs: flattering & 2.88 & 1.05 & .10 & -.07 & $.69^{\prime}$ & .06 & $.12^{*}$ & $.19 * \star$ & .05 & -.10 & $.44^{\star \star \star}$ & $.33^{\star \star *}$ & $.22^{\star \star \star}$ & $.16^{\star \star}$ & $.12^{\star}$ & -.09 & .06 & $.15^{\star \star}$ & .01 & $.14^{\star}$ & -.03 \\
\hline $\begin{array}{l}\text { 4. SITs: rational } \\
\text { influence }\end{array}$ & 5.80 & 0.92 & $.45^{* \star *}$ & $.46^{* \star \star}$ & .04 & $.78^{\prime}$ & $.16^{\star \star}$ & -.01 & $.48^{* * *}$ & $.58^{* * *}$ & $.18^{\star \star \star}$ & $.25^{\star \star \star}$ & .09 & $.48^{* * *}$ & $.57^{* \star *}$ & $-.20^{\star \star \star}$ & $.22^{\star * *}$ & $-.24^{\star \star \star}$ & $.29^{\star \star \star}$ & -.07 & $.50 * * *$ \\
\hline $\begin{array}{l}\text { 5. SITs: exerting } \\
\text { pressure }\end{array}$ & 2.83 & 1.15 & $.19^{\star \star}$ & $.62^{\star \star \star}$ & $.13^{*}$ & $.13^{*}$ & $.75^{\prime}$ & $.68^{\star \star \star}$ & $.36^{\star \star \star}$ & $.12^{\star}$ & $-.30 * * *$ & & & .05 & $.27^{\star \star *}$ & $.15^{\star *}$ & $.27^{* \star *}$ & $-.16^{\star \star}$ & -.01 & $-.36^{\star \star \star}$ & $.17 * *$ \\
\hline $\begin{array}{l}\text { 6. SITs: engaging } \\
\text { superior authority }\end{array}$ & 2.06 & 1.21 & -.04 & $.34^{\star \star \star}$ & $.20 * \star$ & -.03 & $.68^{\star \star \star}$ & $.82^{\prime}$ & $.14^{\star}$ & .02 & 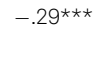 & $-.19 \star \star$ & $-.19 \star \star$ & .05 & $.14^{\star}$ & $.12^{\star}$ & .10 & -.09 & -.01 & $-.15^{\star}$ & .05 \\
\hline 7. Personal initiative & 5.10 & 1.03 & $.77 * \star \star$ & $.56^{\star \star \star}$ & .07 & $.42^{\star \star \star}$ & $.38 * \star \star$ & $.14^{*}$ & $.86^{\prime}$ & $.77^{\star \star \star}$ & $.13^{*}$ & $.28^{* \star \star}$ & $.23^{\star \star \star}$ & $.40 * \star \star$ & $.76^{\star \star \star}$ & $-.14^{\star \star}$ & $.46^{\star \star \star \star}$ & $-.37^{\star \star \star}$ & $.35 * \star \star$ & $-.11 *$ & $.76^{\star \star \star}$ \\
\hline 8. Self-responsibility & 5.42 & 0.69 & $.72^{\star \star \star}$ & $.53^{\star \star \star}$ & -.05 & $.54^{\star \star \star}$ & .09 & .01 & $.76^{\star \star \star}$ & $.74^{\prime}$ & $.13^{*}$ & 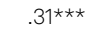 & $.22^{\star \star \star}$ & $.63^{\star \star \star}$ & $.75^{\star \star \star}$ & $-.20^{\star \star \star}$ & $.33^{\star \star \star}$ & $-.41^{\star \star \star \star}$ & $.48^{\star \star \star}$ & -.02 & $.76^{\star \star \star}$ \\
\hline 9. LMX & 4.56 & 1.47 & $.28 * \star \star$ & -.08 & $.41^{* \star \star}$ & 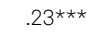 & $-.31^{\star \star \star \star}$ & -.29 *** & $.13^{\star *}$ & $.17^{\star \star *}$ & $.91^{\prime}$ & $.83^{* * *}$ & $.58^{\star \star \star}$ & .08 & $.13^{*}$ & 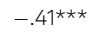 & -.04 & $-.11 *$ & -.05 & $.15^{* *}$ & .03 \\
\hline 10. Job satisfaction & 4.83 & 1.17 & $.39 * \star \star$ & .02 & $.32^{\star \star \star}$ & $.26^{\star \star \star}$ & $-.14^{\star \star}$ & $-.17^{\star \star}$ & $.29 * \star \star$ & $.33^{* * *}$ & $.74^{\star \star \star}$ & $.80^{\prime}$ & $.75^{\star \star \star}$ & $.21^{\star \star \star}$ & $.31^{\star \star \star}$ & 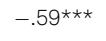 & .09 & $-.33^{\star \star \star \star ~}$ & -.01 & $.26^{\star \star \star}$ & $.20^{\star \star \star *}$ \\
\hline $\begin{array}{l}\text { 11. Organizational } \\
\text { commitment }\end{array}$ & 3.88 & 1.28 & $.22^{\star \star *}$ & $-.12^{\star}$ & $.27 * \star \star$ & .09 & $-.20 * \star \star$ & $-.17^{\star \star *}$ & $.20 * \star \star$ & $.20^{* \star \star}$ & 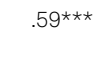 & $.70 * * *$ & $.89^{\prime}$ & $.19 \star \star$ & $.26^{\star \star \star}$ & 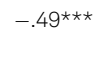 & $.11^{\star}$ & $-.24^{\star \star \star}$ & -.01 & $.27^{\star \star \star}$ & .09 \\
\hline 12. OCBs: helpfulness & 5.50 & 0.80 & $.45^{\star \star *}$ & $.25^{\star \star \star}$ & $.16^{\star \star}$ & $.43^{* * *}$ & .05 & .05 & $.41^{\star \star \star}$ & $.68^{* \star \star}$ & .09 & $.25^{\star \star \star}$ & $.18 * \star$ & $.92^{\prime \prime}$ & $.76^{\star \star \star}$ & -.05 & $.34^{\star \star \star *}$ & -.12 & $.40^{\star \star \star}$ & $.33^{\star \star \star}$ & $.48^{\star \star \star}$ \\
\hline 13. OCBs: initiative & 5.31 & 1.01 & $.80^{\star \star \star}$ & $.58^{* \star \star}$ & $.13^{\star}$ & $.52^{\star \star \star}$ & 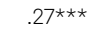 & $.14^{\star}$ & $.77^{\star \star \star}$ & $.76^{\star \star \star}$ & $.14^{*}$ & $.36^{\star \star \star}$ & $.25^{\star \star \star}$ & $.76^{\star \star \star}$ & $.96^{\prime \prime}$ & $-.18^{\star \star}$ & $.43^{\star \star \star}$ & 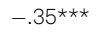 & $.40^{* \star \star}$ & .09 & $.59^{\star \star \star}$ \\
\hline $\begin{array}{l}\text { 14. Emotional } \\
\text { exhaustion }\end{array}$ & 2.42 & 1.10 & $-.12^{\star}$ & .05 & -.08 & $-.18^{\star \star}$ & $.19 * \star$ & $.13^{*}$ & $-.14^{\star}$ & $-.19 \star \star$ & $-.45^{\star \star \star}$ & $-.62^{\star \star *}$ & $-.45^{\star \star \star}$ & -.05 & $-.17 \star \star$ & $.86^{\prime}$ & $-.13^{\star \star}$ & $.60^{* \star \star}$ & .07 & $-.26^{\star \star \star}$ & $-.17^{\star *}$ \\
\hline 15. Extraversion & 4.36 & 1.52 & $.23^{\star \star \star}$ & $.19^{* \star *}$ & .06 & $.18^{\star \star}$ & $.27^{* \star \star}$ & $.13^{*}$ & $.38^{* * *}$ & $.23^{\star \star \star}$ & -.04 & $.11^{\star}$ & .06 & $.27^{* \star \star}$ & $.34 * * *$ & $-.15^{\star \star}$ & $.87^{\prime}$ & $-.36^{\star \star \star}$ & $.32^{\star \star *}$ & $.24^{\star \star *}$ & $.32 * \star *$ \\
\hline 16. Neuroticism & 3.65 & 1.42 & $-.25^{\text {ᄎ** }}$ & $-.18^{\star \star}$ & $.11^{\star}$ & $-.19 * \star$ & $-.11 *$ & -.08 & $-.33^{\star \star \star}$ & $-.36^{\star \star \star}$ & $-.17^{\star \star *}$ & $-.36^{\star * \star}$ & $-.22^{\star \star \star}$ & -.11 & $-.30^{\star \star \star *}$ & $.61^{* * *}$ & $-.27^{\star \star \star \star}$ & $.77^{\prime}$ & .00 & $-.21^{\star \star \star \star}$ & $-.31^{\star \star \star}$ \\
\hline 17. Openness & 5.37 & 1.13 & $.33^{\star \star \star}$ & $.29 * \star \star$ & .00 & $.23^{\star \star \star}$ & .02 & .01 & $.38 * \star \star$ & $.48 * \star \star$ & -.05 & -.01 & -.01 & 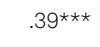 & $.41^{\star \star \star}$ & .02 & $.21 * \star \star$ & -.04 & $.82^{\prime}$ & .00 & 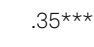 \\
\hline 18. Agreeableness & 4.49 & 1.16 & -.04 & $-.22^{\star \star \star *}$ & $.13^{*}$ & -.08 & $-.36 * * *$ & $-.15^{\star}$ & -.11 & .03 & $.17 * *$ & $.25^{\star \star \star}$ & $.24^{\star \star \star}$ & $.33^{* \star *}$ & .09 & $-.27^{\star \star \star}$ & $-.23 * \star \star$ & .03 & 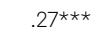 & $.70^{\prime}$ & -.05 \\
\hline 19. Conscientiousness & 5.36 & 0.91 & $.69^{\star \star \star *}$ & $.44^{\star \star \star}$ & -.03 & $.43^{\star \star \star}$ & $.17 \star \star$ & .05 & $.76^{\star \star \star}$ & $.73^{* * *}$ & .05 & $.23^{\star \star \star}$ & .06 & $.48^{* \star *}$ & $.59 * \star \star *$ & $-.17 \star \star$ & $-.25^{\star \star *}$ & $.34 * \star \star x$ & $.26 * \star \star$ & -.05 & $.66^{\prime}$ \\
\hline
\end{tabular}

Note $A C O=$ ant colny optimization; $\mathrm{LMX}=$ leader-member exchange $\mathrm{OCB}=$ organizational citizenship behavior: SITs = subordinate influence tactics. $\mathrm{N}=413$. Values along the diagonal represent internal consistency (' $\omega$ or " $\omega_{s}$ ). Values above the diagonal represent the correlations for study variables in the initial form (i.e., without $\left.A C 0\right)$ ). ${ }^{\star} p<.05,{ }^{\star \star} p<.01,{ }^{* \star *} p<.001$. 
the ICT subscale factor, $\omega_{\mathrm{s}}$ was .84 (95\% CI \pm .69 ). Furthermore, Table 2 additionally contains the intercorrelations of all latent models based on the initial versions of the external instruments (i.e., without ACO).

\section{Results for Convergent and Discriminant Validity}

Our findings revealed a significant and strong correlation of AE with personal initiative, $r=.77, p<.001$. The correlation of AE with the SIT "rational influence" was also significant, but slightly below moderate, $r=.45, p<.001$. Small correlations were found between AE and the SITs "exerting pressure," $r=.19, p=.001$, and "engaging superior authority," $r=-.04, p=.55$, and "flattering," $r=.10$, $p=.07$. Thus, Hypothesis 2 was only partly supported.

ICT was positively and moderately related to selfresponsibility, $r=.53, p<.001$, and to the SIT "exerting pressure," $r=.62, p<.001$. Significant but smaller correlations were observed between ICT and the SITs "rational influence," $r=.46, p<.001$, and "engaging superior authority," $r=.34, p<.001$. However, we did not find a significant relationship of ICT with the SIT "flattering," $r=-.07, p=.26$. Hence, Hypothesis 3 was partially supported.

AE correlated slightly stronger with LMX than we expected (i.e., $r \leq .20$ ), $r=.28, p<.001$. Still, we observed a weak correlation of AE with LMX. No significant correlation was found for ICT and LMX, $r=-.08, p=.16$. Thus, Hypothesis 4 was predominantly supported, and Hypothesis 5 was fully supported.

\section{Results for Criterion-Related Validity}

Our findings revealed significant positive correlations of AE with job satisfaction, $r=.39, p<.001$, and with organizational commitment, $r=.22$, $p<.001$. Hence, Hypothesis 6 was supported. ICT was negatively but rather weakly related to organizational commitment, $r=-.12, p=$ .04. Since we did not find the predicted negative correlation between ICT and job satisfaction, $r=-.02, p=.78$, Hypothesis 7 was only partly supported. AE correlated positively with both OCB dimensions: "helpfulness," $r=$ $.45, p<.001$, and "initiative," $r=.80, p<.001$. ICT also correlated with "helpfulness," $r=.25, p<.001$, and "initiative," $r=.58, p<.001$. Hence, Hypothesis 8 was supported. AE correlated slightly negatively with emotional exhaustion, $r=-.12, p=.03$, while we did not observe the expected negative correlation of ICT with emotional exhaustion, $r=.05, p=.38$. Therefore, Hypothesis 9 was only partly supported.

\section{Results for Incremental Validity}

We also examined the incremental validity of AE and ICT in predicting job-related outcome variables above and beyond broad personality traits. The results of the hierarchical regression analyses are presented in Tables 3 and 4. Importantly, AE and ICT accounted for variance increments in all outcome variables. In fact, AE and ICT predicted incremental variance in job satisfaction with $\Delta R^{2}=.09, p<.001$, indicating a small effect (Cohen, 1988) of $f^{2}=0.12$. Similarly, AE and ICT explained incremental variance in organizational commitment, $\Delta R^{2}=.07, p<$ .001 , indicating a small effect of $f^{2}=0.08$. A moderate incremental contribution occurred for the OCB "initiative," $\Delta R^{2}=.18, p<.001$, with a medium effect size (Cohen, 1988) of $f^{2}=0.33$. Small incremental contributions were observed for the prediction of OCB "helpfulness," $\Delta R^{2}=.03, p=.001, f^{2}=0.04$, and for emotional exhaustion, $\Delta R^{2}=.02, p=.003, f^{2}=0.03$.

\section{Discussion}

The aim of our two studies was to examine the psychometric properties of a German version of Kelley's (1992) followership questionnaire. We found a two-factor structure in our data, equivalent to the original validation study by Blanchard et al. (2009) and the validation study by Gatti et al. (2014). The items did not unanimously load on the two factors that Kelley (1992) had predicted. However, this was also the case in the prior validation studies (Blanchard et al., 2009; Gatti et al., 2014). Still, in accordance with Blanchard et al. (2009), the two identified factors can be interpreted as AE and ICT. A CFA of the resulting 14-item questionnaire showed an adequate model fit (Hopwood \& Donnellan, 2010; Olaru et al., 2019). In addition, the fit was comparable to previous findings (Gatti et al., 2014) although the followership model could not reach all recommended cutoff values for a good model fit. However, Hopwood and Donnellan (2010) argued that previous studies might provide a more reasonable context for interpreting overall fit statistics than the rules of thumb widely used for model fit evaluation. Specifically, they concluded that the inherent complexity of personality measures often leads to poorer model fit statistics in a CFA (Hopwood \& Donnellan, 2010). Thus, the presented fit of the followership model can be described as reasonable.

Furthermore, because relying on general cutoff values was repeatedly criticized (e.g., Greiff \& Heene, 2017; Ropovik, 2015), we used a combination of confirmatory and exploratory analyses to reduce the risk of misspecification (Ropovik, 2015). In addition, we tried to detect local misspecification based on modification indices (Saris et al., 2009). While the misspecification method pointed to some potentially problematic items in the followership model, we could only find one consistent 
Table 3. Incremental validity of AE and ICT for job satisfaction and organizational commitment

\begin{tabular}{|c|c|c|c|c|c|c|c|c|c|c|}
\hline \multirow[b]{2}{*}{ Variable } & \multicolumn{5}{|c|}{ Job satisfaction } & \multicolumn{5}{|c|}{ Organizational commitment } \\
\hline & $B$ & SE B & $\beta$ & $R^{2}$ & $\Delta R^{2}$ & $B$ & SE B & $\beta$ & $R^{2}$ & $\Delta R^{2}$ \\
\hline Step 1 & & & & .14 & $.14^{\star \star \star}$ & & & & .06 & $.06^{\star \star \star}$ \\
\hline Extraversion & -0.04 & 0.04 & -.05 & & & -0.03 & 0.05 & -.04 & & \\
\hline Neuroticism & -0.21 & 0.04 & $-.25^{\star \star \star}$ & & & -0.13 & 0.05 & $-.14^{\star \star}$ & & \\
\hline Openness & -0.05 & 0.05 & -.05 & & & -0.01 & 0.06 & -.01 & & \\
\hline Agreeableness & 0.19 & 0.05 & 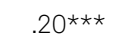 & & & 0.22 & 0.06 & 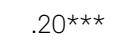 & & \\
\hline Conscientiousness & 0.17 & 0.06 & $.14^{\star \star}$ & & & 0.02 & 0.08 & .02 & & \\
\hline Step 2 & & & & .23 & $.09 * \star \star$ & & & & .13 & $.07^{\star \star \star}$ \\
\hline$A E$ & 0.53 & 0.08 & $.36 * \star \star$ & & & 0.45 & 0.10 & $.27^{\star \star \star}$ & & \\
\hline ICT & -0.24 & 0.06 & $-.20 \star \star \star$ & & & -0.30 & 0.08 & $-.23^{\star \star \star}$ & & \\
\hline
\end{tabular}

Note. $N=413 .{ }^{* \star} p<.01,{ }^{* \star} p<.001$.

Table 4. Incremental validity of $\mathrm{AE}$ and ICT for OCBs and emotional exhaustion

\begin{tabular}{|c|c|c|c|c|c|c|c|c|c|c|c|c|c|c|c|}
\hline \multirow[b]{2}{*}{ Variable } & \multicolumn{5}{|c|}{ OCBs: helpfulness } & \multicolumn{5}{|c|}{ OCBs: initiative } & \multicolumn{5}{|c|}{ Emotional exhaustion } \\
\hline & $B$ & SE B & $\beta$ & $R^{2}$ & $\Delta R^{2}$ & $B$ & SE B & $\beta$ & $R^{2}$ & $\Delta R^{2}$ & $B$ & SE B & $\beta$ & $R^{2}$ & $\Delta R^{2}$ \\
\hline Step 1 & & & & .23 & $.23 * \star \star$ & & & & .27 & 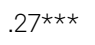 & & & & .26 & $.26^{\star \star \star}$ \\
\hline Extraversion & 0.04 & 0.03 & .07 & & & 0.09 & 0.03 & $.13^{\star \star}$ & & & -0.01 & 0.04 & -.01 & & \\
\hline Neuroticism & 0.00 & 0.03 & .00 & & & -0.11 & 0.03 & $-.15^{\star \star}$ & & & 0.36 & 0.04 & $.46^{\star \star \star}$ & & \\
\hline Openness & 0.14 & 0.03 & $.19 * \star \star$ & & & .19 & 0.04 & $.21^{\star \star \star}$ & & & 0.06 & 0.05 & .06 & & \\
\hline Agreeableness & 0.17 & 0.03 & $.24^{\star \star \star}$ & & & -0.00 & 0.04 & .00 & & & -0.14 & 0.05 & $-.14^{\star \star}$ & & \\
\hline Conscientiousness & 0.23 & 0.04 & $.26 * \star \star$ & & & 0.34 & 0.05 & $.31 * \star \star$ & & & -0.05 & 0.06 & -.04 & & \\
\hline Step 2 & & & & .26 & $.03^{* \star}$ & & & & .45 & $.18 * \star \star$ & & & & .28 & $.02^{\star \star}$ \\
\hline$A E$ & 0.20 & 0.06 & $.20 \star \star$ & & & 0.58 & 0.06 & $.46^{\star \star *}$ & & & -0.10 & 0.08 & -.07 & & \\
\hline $\mathrm{ICT}$ & 0.01 & 0.04 & .01 & & & 0.11 & 0.05 & $.10^{\star}$ & & & 0.20 & 0.06 & $.18^{\star \star}$ & & \\
\hline
\end{tabular}

Note. $O C B=$ organizational citizenship behavior. $N=413 .{ }^{\star} p<.05,{ }^{* \star} p<.01,{ }^{* \star \star} p<.001$.

misspecification across Study 1 and Study 2. Consequently, we allowed residual correlations between the two items "personally identify" and "actively develop" as this was a plausible adjustment. Since the substantial residual correlation was replicated across two studies, mere specifics of a sample can be ruled out. We can only speculate about the commonality of the two items "personally identify" ("Instead of waiting for or merely accepting what the leader tells you, do you personally identify which organizational activities are most critical for achieving the organization's priority goals?") and "actively develop" ("Do you actively develop a distinctive competence in those critical activities so that you become more valuable to the leader and the organization?") beyond the active engagement factor. The direct reference made in one item to the other may be one reason. Future research may examine whether the residual correlation also emerges if the two items are not presented next to each other and the direct reference ("those critical activities") is replaced. From a followership perspective, another plausible commonality of the two concerned items may be that they reflect the efforts to achieve overarching organizational goals, which is also in line with Kelley's (1992) definition of followership, while the other followership items more specifically refer to the leader or group level. To substantiate this conjecture, further research is needed to test the effects of followership behaviors with different foci. The decision to keep both items or exclude one item does, however, not seem to be very important: When we dropped one of the two items ("actively develop"), thus accounting for the potential redundancy in these items, the correlations with other variables remained unchanged (see Table 2 and ESM 8).

Furthermore, we tested the convergent, discriminant, and criterion-related validity. Some correlations obtained with instruments included for establishing convergent and discriminant validity seem noteworthy. We found several correlations supporting the convergent validity of the two dimensions. For instance, AE strongly correlated with personal initiative at work. ICT was moderately related to self-responsibility. However, the positive correlation of $\mathrm{AE}$ with self-responsibility was even higher. Note that as a 
result of our factor analyses, the $\mathrm{AE}$ dimension became broader in scope. In the current version, $\mathrm{AE}$ includes, for instance, thinking up new ideas and solving tough problems. These behaviors should indeed relate to selfresponsibility. We also observed that not all SITs were unanimously related to $\mathrm{AE}$ and ICT. It makes sense, however, that the SITs "exerting pressure" and "engaging superior authority" were more strongly related to ICT, which comprises followership behavior that may cause conflicts with a supervisor. As expected, we found only small correlations of LMX with AE and ICT, indicating discriminant validity. Importantly, correlations of the followership dimensions with variables that we considered as convergent indicators were considerably higher than those obtained with LMX.

In testing criterion-related validity, we found comparable results to previous findings regarding job satisfaction, organizational commitment, OCBs, emotional exhaustion, LMX, and extraversion (Blanchard et al., 2009; Gatti et al., 2014). We also extended the nomological network by exploring relations of followership behaviors with these important organizational constructs while controlling for the influence of personality traits. AE and ICT both accounted for variance increments in all outcome variables above and beyond broad personality traits. Hence, our findings reveal that an active approach to followership is associated with desired organizational outcomes. This is in line with the argument of Uhl-Bien et al. (2014) that followership is essential for better understanding leadership because it contributes to the understanding of how more or less effective followership behavior contributes to the leadership process.

However, we also observed correlations indicating that ICT is not always positively associated with desired leadership outcomes. In accordance with our hypotheses, ICT was negatively related to organizational commitment and did not correlate with job satisfaction. These results do not correspond with Kelley's (1992) assumption that active and critical followers are the most effective. This assumption may thus not apply as broadly as expected by Kelley. For instance, there might be leaders who do not want followers to act too independently. Thus, the effectiveness of followership might depend on the fit of implicit role expectations between followers and their leaders (Carsten et al., 2010, 2018). Hence, more empirical work in the field of followership is needed to better understand the impact, interaction, and potential boundary conditions of active and critical followership behaviors within organizations.

Our validation study opens further concrete avenues for future research. The German instrument can be used to assess followership behaviors within German organizations and to compare followership behaviors in Germany with other countries. Such research is called for because of an increasing number of global work teams and since cultural differences between countries might affect the relationships between followership, leadership, and organizational outcomes (e.g., via varying power distance or institutional collectivism; e.g., Haire et al., 1966; House et al., 2004). Another particularly promising and innovative direction for future research could be to complement effective leadership training with appropriate followership development programs (Bufalino, 2018).

\section{Limitations}

There are several limitations to this study. Since we adapted a questionnaire to measure followership behaviors, we only collected self-report data. The relatively high mean values for the followership dimensions might indicate certain risks of social desirability. To address related problems, future research could match the subjective evaluations of followers with their leaders' perceptions (Gatti et al., 2014). Furthermore, our analysis was based on cross-sectional data. Future research should investigate the reported relations especially for criterion-related validity in longitudinal studies to get indications for the causality underlying them.

We found evidence for the factorial structure, internal consistency, convergent, discriminant, and criterionrelated validity for our German translation of Kelley's (1992) followership questionnaire. With this, we provide a basis for further followership research in Germanspeaking countries. However, we recommend future research to pay attention to potential local misspecifications of the followership model. Furthermore, we point to the broad interpretation of what we used as convergent indicators, since no other followership questionnaire in German was available. In addition, we had to adjust most of the instruments we used in this study to achieve adequate model fit, which reduces their comparability to other studies.

\section{Conclusion}

The German version of Kelley's (1992) followership questionnaire showed the intended factorial structure and was related to meaningful organizational variables. We hope that the availability of this followership questionnaire can facilitate future research, both on followership and on leadership. The final German questionnaire is provided in ESM 2. 


\section{Electronic Supplementary Material}

The electronic supplementary material is available with the online version of the article at https://doi.org/ 10.1027/2698-1866/a000005

ESM 1. Careless response detection

ESM 2. German items and translation process

ESM 3. Followership item and scale analysis

ESM 4. CFA results, Study 1

ESM 5. Local misspecification detection

ESM 6. Study 2 instruments

ESM 7. Ant Colony Optimization

ESM 8. Correlations without "actively develop"

\section{References}

Baker, S. D. (2007). Followership. The theoretical foundation of a contemporary construct. Journal of Leadership \& Organizational Studies, 14(1), 50-60. https://doi.org/10.1177/0002831207304343

Barrick, M. R., Parks, L., \& Mount, M. K. (2005). Self-monitoring as a moderator of the relationships between personality traits and performance. Personnel Psychology, 58(3), 745-767. https://doi. org/10.1111/j.1744-6570.2005.00716.x

Bierhoff, H., Wegge, J., Bipp, T., Kleinbeck, U., Attig-Grabosch, C., \& Schulz, S. (2005). Entwicklung eines fragebogens zur Messung von Eigenverantwortung oder: "Es gibt nichts Gutes, außer man tut es" [Development of a questionnaire to measure self-responsibility or: "Don't talk about it, just do it"]. Zeitschrift Für Personalpsychologie, 4(1), 4-18. https://doi.org/10.1026/1617-6391.4.1.4

Blanchard, A. L., Welbourne, J. L., Gilmore, D., \& Bullock, A. (2009). Followership styles and employee attachment to the organization. The Psychologist-Manager Journal, 12(2), 111-131. https:// doi.org/10.1080/10887150902888718

Blickle, G., \& Gönner, S. (1999). Studien zur Validierung eines Inventars zur Erfassung intraorganisationaler Einflußstrategien [Validating an inventory to assess intraorganizational influence strategies]. Diagnostica, 45(1), 35-46. https://doi.org/10.1026// 0012-1924.45.1.35

Bracken, B. A., \& Barona, A. (1991). State of the art procedures for translating, validating and using psychoeducational tests in cross-cultural assessment. School Psychology International, 12(1-2), 119-132. https://doi.org/10.1177/0143034391121010

Bufalino, G. (2018). Followership under the spotlight: Implications for followership development. Industrial and Commercial Training, 50(2), 55-60. https://doi.org/10.1108/ICT-04-2017-0028

Campbell, D. T., \& Fiske, D. W. (1959). Convergent and discriminant validation by the multitrait-multimethod matrix. Psychological Bulletin, 56(2), 81-105. https://doi.org/10.1037/h0046016

Carsten, M. K., Uhl-Bien, M., \& Huang, L. (2018). Leader perceptions and motivation as outcomes of followership role orientation and behavior. Leadership, 14(6), 731-756. https://doi.org/10.1177/1742715017720306

Carsten, M. K., Uhl-Bien, M., West, B. J., Patera, J. L., \& McGregor, R. (2010). Exploring social constructions of followership: A qualitative study. The Leadership Quarterly, 21(3), 543-562. https://doi.org/10.1016/j.leaqua.2010.03.015

Chaleff, I. (1995). The courageous follower. Standing up to and for our leaders. Berrett-Koehler.

Cohen, J. (1988). Statistical power analysis for the behavioral sciences. Routledge.
Cole, D. A., Ciesla, J. A., \& Steiger, J. H. (2007). The insidious effects of failing to include design-driven correlated residuals in latentvariable covariance structure analysis. Psychological Methods, 12(4), 381-398. https://doi.org/10.1037/1082-989X.12.4.381

Cook, K. F., Kallen, M. A., \& Amtmann, D. (2009). Having a fit: Impact of number of items and distribution of data on traditional criteria for assessing IRT's unidimensionality assumption. Quality of Life Research, 18(4), 447-460. https:// doi.org/10.1007/s11136-009-9464-4

Demerouti, E., Bakker, A. B., Nachreiner, F., \& Schaufeli, W. B. (2001). The job demands-resources model of burnout. Journal of Applied Psychology, 86(3), 499-512. https://doi.org/10.1037/ 0021-9010.86.3.499

Dinh, J. E., Lord, R. G., Gardner, W. L., Meuser, J. D., Liden, R. C., \& $\mathrm{Hu}$, J. (2014). Leadership theory and research in the new millennium: Current theoretical trends and changing perspectives. The Leadership Quarterly, 25(1), 36-62. https://doi.org/10.1016/j. leaqua.2013.11.005

Enzmann, D., \& Kleiber, D. (1989). Helfer-Leiden: Streß und Burnout in psychosozialen Berufen [Helpers' ordeals: Stress and burnout in psychosocial professions]. Asanger.

Fabrigar, L. R., Wegener, D. T., MacCallum, R. C., \& Strahan, E. J. (1999). Evaluating the use of exploratory factor analysis in psychological research. Psychological Methods, 4(3), 272-299. https://doi.org/10.1037/1082-989X.4.3.272

Faul, F., Erdfelder, E., Lang, A.-G., \& Buchner, A. (2007). G*Power 3: A flexible statistical power analysis program for the social, behavioral, and biomedical sciences. Behavior Research Methods, 39(2), 175-191. https://doi.org/10.3758/BF03193146

Festinger, L. (1957). A theory of cognitive dissonance. Stanford University Press.

Frese, M., Fay, D., Hilburger, T., Leng, K., \& Tag, A. (1997). The concept of personal initiative: Operationalization, reliability and validity in two German samples. Journal of Occupational and Organizational Psychology, 70(2), 139-161. https://doi.org/10.1111/ j.2044-8325.1997.tb00639.x

Gatti, P., Tartari, M., Cortese, C. G., \& Ghislieri, C. (2014). A contribution to the Italian validation of Kelley's followership questionnaire. Testing, Psychometrics, Methodology in Applied Psychology, 21(1), 67-87. https://doi.org/10.4473/TPM21.1.5

Graen, G. B., \& Uhl-Bien, M. (1995). Relationship-based approach to leadership: Development of leader-member exchange (LMX) theory of leadership over 25 years: Applying a multi-level multidomain perspective. The Leadership Quarterly, 6(2), 219-247. https://doi.org/10.1016/1048-9843(95)90036-5

Greiff, S., \& Heene, M. (2017). Why psychological assessment needs to start worrying about model fit. European Journal of Psychological Assessment, 33(5), 313-317. https://doi.org/10.1027/ 1015-5759/a000450

Haire, M., Ghiselli, E. E., \& Porter, L. W. (1966). Managerial thinking: An international study. John Wiley \& Sons.

Hobfoll, S. E., Lilly, R. S., \& Jackson, A. P. (1992). Conservation of social resources and the self. In H. Veiel \& U. Baumann (Eds.), The series in clinical and community psychology. The meaning and measurement of social support (pp. 125-141). Hemisphere. https://doi.org/10.1037/t08391-000

Holland, J. L. (1996). Exploring careers with a typology: What we have learned and some new directions. American Psychologist, 51(4), 397-406. https://doi.org/10.1037/0003-066X.51.4.397

Hopwood, C. J., \& Donnellan, M. B. (2010). How should the internal structure of personality inventories be evaluated? Personality and Social Psychology Review, 14(3), 332-346. https://doi.org/ 10.1177/1088868310361240

Horn, J. L. (1965). A rationale and test for the number of factors in factor analysis. Psychometrika, 30(2), 179-185. https://doi.org/ 10.1007/BF02289447 
House, R. J., Hanges, P. J., Javidan, M., Dorfman, P. W., Gupta, V., \& GLOBE associates. (2004). Culture, leadership, and organizations: The GLOBE Study of 62 Societies. Sage.

Hurwitz, M., \& Hurwitz, S. (2015). Leadership is half the story. A fresh look at followership, leadership, and collaboration. University of Toronto Press. https://doi.org/10.3138/ 9781442622395

Kellerman, B. (2008). Followership. How followers are creating change and changing leaders. Harvard Business Press.

Kelley, R. E. (1988, November). In praise of followers. Harvard Business Review. https://hbr.org/1988/11/in-praise-of-followers

Kelley, R. E. (1992). The power of followership. How to create leaders people want to follow and followers who lead themselves. Doubleday Currency.

Landis, R. S., Edwards, B. D., \& Cortina, J. M. (2009). On the practice of allowing correlated residuals among indicators in structural equation models. In C. E. Lance \& R. J. Vandenberg (Eds.), Statistical and methodological myths and urban legends: Doctrine, verity and fable in the organizational and social sciences (pp. 193-214). Routledge.

Leiner, D. J. (2016). Our research's breadth lives on convenience samples. A case study of the online respondent pool "SoSci Panel". Studies in Communication, 5(4), 367-396. https://doi. org/10.5771/2192-4007-2016-4-36769-134

Locke, E. A. (1976). The nature and causes of job satisfaction. In M. D. Dunnette (Ed.), Handbook of industrial and organizational psychology (Vol. 1, pp. 1297-1349). Rand McNally.

Lord, R. G., Day, D. V., Zaccaro, S. J., Avolio, B. J., \& Eagly, A. H. (2017). Leadership in applied psychology: Three waves of theory and research. Journal of Applied Psychology, 102(3), 434-451. https://doi.org/10.1037/apl0000089

Maier, G. W., \& Woschée, R. M. (2002). Die affektive Bindung an das Unternehmen: Psychometrische Überprüfung einer deutschsprachigen Fassung des Organizational Commitment Questionnaire (OCQ) von Porter und Smith (1970) [Affective commitment to an organization: Psychometric examination of a German version of the Organizational Commitment Questionnaire (OCQ) of Porter and Smith (1970)]. Zeitschrift Für Arbeitsund Organisationspsychologie A\&0, 46(3), 126-136. https://doi. org/10.1026//0932-4089.46.3.126

Maslach, C., \& Jackson, S. E. (1986). The Maslach Burnout Inventory Manual. Consulting Psychologists Press.

McCrae, R. R., \& Costa, P. T., Jr. (2003). Personality in adulthood: A five-factor theory perspective. Guilford Press. https://doi.org/10. 4324/9780203428412

McDonald, R. P. (1978). Generalizability in factorable domains: "Domain validity and generalizability": 1. Educational and Psychological Measurement, 38(1), 75-79. https://doi.org/10.1177/ 001316447803800111

Meade, A. W., \& Craig, S. B. (2012). Identifying careless responses in survey data. Psychological Methods, 17(3), 437-455. https://doi. org/10.1037/a0028085

Meyer, J. P., \& Allen, N. J. (1991). A three-component conceptualization of organizational commitment. Human Resource Management Review, 1(1), 61-89. https://doi.org/10.1016/10534822(91)90011-Z

Moshagen, M., \& Erdfelder, E. (2016). A new strategy for testing structural equation models. Structural Equation Modeling: A Multidisciplinary Journal, 23(1), 54-60. https://doi.org/10.1080/ 10705511.2014.950896

Mowday, R. T., Steers, R. M., \& Porter, L. (1979). The measurement of organizational commitment. Journal of Vocational Behavior, 14(2), 224-247. https://doi.org/10.1016/0001-8791(79)90072-1
Muthén, L. K., \& Muthén, B. O. (2015). Mplus (Version 7.4) [Computer software]. Muthén \& Muthén.

Nübling, M., Stößel, U., Hasselhorn, H.-M., Michaelis, M., \& Hofmann, F. (2005). Methoden zur Erfassung psychischer Belastungen Erprobung eines Messinstrumentes (COPSOQ) Bremerhaven [Schriftenreihe der Bundesanstalt für Arbeitsschutz und Arbeitsmedizin; Fb 1058]: Wirtschaftsverlag NW.

Oc, B., \& Bashur, M. R. (2013). Followership, leadership and social influence. The Leadership Quarterly, 24(6), 919-934. https://doi. org/10.1016/j.leaqua.2013.10.006

Olaru, G., Schroeders, U., Hartung, J., \& Wilhelm, O. (2019). Ant colony optimization and local weighted structural equation modeling. A tutorial on novel item and person sampling procedures for personality research. European Journal of Personality, 33(3), 400-419. https://doi.org/10.1002/per.2195

Organ, D. W. (1988). Organizational citizenship behavior: The good soldier syndrome. Lexington Books/DC Heath and Com.

Rammstedt, B., \& John, O. P. (2005). Kurzversion des Big Five Inventory (BFI-K): Entwicklung und Validierung eines ökonomischen Inventars zur Erfassung der fünf Faktoren der Persönlichkeit [Short version of the Big Five Inventory (BFI-K): Development and validation of an economic inventory for assessment of the five factors of personality]. Diagnostica, 51(4), 195-206. https://doi.org/10.1026/00121924.51.4.195

Ribbat, M., Krumm, S., \& Hüffmeier, J. (2020). A German Version of Kelley's (1992) Followership Questionnaire [Data set]. https:// osf.io/mvg8x/?view_only=de6efdf9a5044430a785d847c27e1e2d

Rodriguez, A., Reise, S. P., \& Haviland, M. G. (2016). Applying bifactor statistical indices in the evaluation of psychological measures. Journal of Personality Assessment, 98(3), 223-237. https://doi.org/10.1080/00223891.2015.1089249

Ropovik, I. (2015). A cautionary note on testing latent variable models. Frontiers in Psychology, 6(1715), 1-8. https://doi.org/10. 3389/fpsyg.2015.01715

Saris, W. E., Satorra, A., \& van der Veld, W. M. (2009). Testing structural equation models or detection of misspecifications. Structural Equation Modeling, 16(4), 561-582. https://doi.org/10. 1080/10705510903203433

Schyns, B. (2002). Überprüfung einer deutschsprachigen Skala zum Leader-Member-Exchange-Ansatz [Evaluation of a German Scale for Leader-Member Exchange]. Zeitschrift für Differentielle und Diagnostische Psychologie, 23(2), 235-245. https:// doi.org/10.1024//0170-1789.23.2.235

Staufenbiel, T., \& Hartz, C. (2000). Organizational citizenship behavior: Entwicklung und erste Validierung eines Meßinstruments [Organizational Citizenship Behavior: Development and validation of a measurement instrument]. Diagnostica, 46(2), 73-83. https://doi.org/10.1026//0012-1924.46.2.73

Uhl-Bien, M., Riggio, R. E., Lowe, K. B., \& Carsten, M. K. (2014). Followership theory: A review and research agenda. The Leadership Quarterly, 25(1), 83-104. https://doi.org/10.1016/j. leaqua.2013.11.007

Watkins, M. W. (2013). Omega (Version 1.0.0.1) [Computer Software] Ed \& Psych Associates.

West, S. G., Taylor, A. B., \& Wu, W. (2012). Model fit and model selection in structural equation modeling. In R. H. Hoyle (Ed.), Handbook of structural equation modeling (pp. 209-231). The Guilford Press.

Wright, T. A., \& Cropanzano, R. (1998). Emotional exhaustion as a predictor of job performance and voluntary turnover. Journal of Applied Psychology, 83(3), 486-493. https://doi.org/10.1037/ 0021-9010.83.3.486 


\section{History}

Received February 12, 2020

Revision received September 23, 2020

Accepted September 29, 2020

Published online January 19, 2021

Section: I/O Psychology

\section{Open Data}

Data and codes of the presented studies can be found here: https:// osf.io/mvg8x/?view_only=de6efdf9a5044430a785d847c27e1e2d
ORCID

Mirko Ribbat

(iD) https://orcid.org/0000-0001-7449-3096

\section{Mirko Ribbat}

Federal Institute for Occupational Safety and Health

Friedrich-Henkel-Weg 1-25

44149 Dortmund

Germany

ribbat.mirko@baua.bund.de 